\title{
Paroxetine was effective for reducing symptoms in social phobia
}

Baldwin D, Bobes J, Stein DJ, et al, on behalf of the Paroxetine Study Group. Paroxetine in social phobia/social anxiety disorder. Randomised, double-blind, placebo-controlled study. Br J Psychiatry 1999 Aug;175:120-6.

\section{QUESTION: In patients with social phobia, is paroxetine effective for reducing symptoms?}

\section{Design}

Randomised \{allocation concealed*\}†, blinded \{clinicians, patients, outcome assessors, and statisticians $\}^{* \dagger}$, placebo controlled trial with 12 week follow up.

\section{Setting}

39 centres in Belgium, France, Germany, Ireland, South Africa, Spain, and the United Kingdom.

\section{Patients}

290 patients who were $\geqslant 18$ years of age (mean age $36 \mathrm{y}$, $54 \%$ women) and had a primary diagnosis of social phobia according to the Diagnostic and Statistical Manual of Mental Disorders, Fourth Edition, criteria. Exclusion criteria included any other recent Axis 1 disorder, serious medical disorders, or recent use of psychotropic drugs or psychotherapy. $73 \%$ of patients completed the study, and $97 \%$ were analysed.

\section{Intervention}

Patients were allocated to paroxetine, $20 \mathrm{mg}$ /day initially and increased by $10 \mathrm{mg} /$ day as needed to a maximum of $50 \mathrm{mg} /$ day (mean dose $34.7 \mathrm{mg} / \mathrm{d})(\mathrm{n}=139)$, or to placebo $(\mathrm{n}=151)$ for 12 weeks.

Paroxetine v placebo for social phobia at 12 weeksई

\begin{tabular}{lllll} 
Outcome & Paroxetine & Placebo & RBI (95\% Cl) & NNT (CI) \\
Treatment response & $66 \%$ & $32 \%$ & $103 \%(57$ to 166$)$ & 4 (3 to 5$)$ \\
\hline
\end{tabular}

§Abbreviations defined in glossary; $\mathrm{RBI}, \mathrm{NNT}$, and $\mathrm{Cl}$ calculated from data in article.

\section{Main outcome measures}

Mean change in scores on the Liebowitz Social Anxiety Scale (LSAS, maximum score 144 points) and the proportion of responders on the Clinical Global Impression (CGI) scale (maximum score 7 points). Secondary outcomes included the score on the Social Avoidance and Distress Scale (maximum score 28 points).

\section{Main results}

More patients in the paroxetine group than in the placebo group were treatment responders $(\mathrm{p}<0.001)$ (table). Paroxetine led to greater improvement from baseline than did placebo in scores on the LSAS \{difference in mean change from baseline $13.8,95 \%$ CI 6.1 to $21.5\} \$$ the Social Avoidance and Distress Scale \{difference in mean change from baseline $3.3,1.4$ to 5.3$\} \ddagger$ and the CGI \{difference in mean change from baseline 0.7, CI 0.4 to 1.0 .

\section{Conclusion}

In patients with social phobia, paroxetine was effective for reducing symptoms.

*See glossary.

$\dagger$ Information supplied by author.

\$Difference in mean change and CI calculated from data in article.
Source of funding: SmithKline Beecham Pharmaceuticals.

For correspondence: Dr D Baldwin, Mental Health Group,

University of

Southampton, Royal

South Hants Hospital,

Brintons Terrace,

Southampton

SO14 OYG, UK. Fax

$+44(0) 1703234243$

\section{COMMENTARY}

Social phobia is a situationally linked, intense, irrational, persistent fear of being scrutinised or negatively evaluated by others ${ }^{1}$ and is associated with fear of humiliation or embarrassment. ${ }^{2}$ Thus, socially demanding situations become disabling. Patients are cognitively aware of the irrationality of their fear. Prevalence rates are about $13 \%$ for lifetime ${ }^{3}$ and $7 \%$ at 1 year. ${ }^{1-3}$. The presence of social phobia increases the risk for mental, drug, and alcohol comorbid illnesses. ${ }^{1}$ If the condition remains untreated, it can become chronic and unremitting, leading to education and employment difficulties. ${ }^{14}$

Cognitive behaviour therapy with or without antidepressants is the most effective treatment. ${ }^{1}$ However, properly administered therapy is not available, affordable, or obtainable for most people with social phobia. Current drug options are selective serotonin reuptake inhibitors (SSRIs), monoamine oxidase inhibitors, and benzodiazepines. Little evidence exists for the effectiveness of tricyclic antidepressants. ${ }^{1}$

The study by Baldwin and colleagues and the current deluge of consumer education and marketing illuminate this hidden, underdiagnosed anxiety disorder. A crossover design would yield even more information and would perhaps address the effects after 12 weeks of treatment or after discontinuation. As is often the case, the sample was selected: patients had pure social phobia, no comorbid conditions, and no history of failed SSRI therapy for any illness. Excluding previous non-responders biases the results toward SSRI efficacy. This luxury does not exist in the office where initial treatment occurs. However, the overall results of this study support using paroxetine to treat social phobia initially; other data also support using other SSRIs and treatments. ${ }^{1}$ The main message is the importance of recognising and diagnosing this under recognised, debilitating illness because of the tremendous implications for quality of life.

Stephen A Wilson, MD University of Pittsburgh Medical Center, St. Margaret Pittsburgh, Pennsylvania, USA

1 Bruce TJ, Saeed SA. Am Fam Physician 1999;60:2311-20.

2 American Psychiatric Association, Task Force on DSM-IV. Diagnostic and Statistical Manual of Mental Disorders:DSM-IV. 4th ed. Washington, DC: American Psychiatric Association; 1994.

3 MCP Hahnemann University Social Anxiety Treatment Program. http://www.mcphu.edu/shp/fear/\#3.

4 Davidson JR. J Clin Psychiatry 1998;59(Suppl 17):47-53. 